\title{
S BBBLION
}

Слезин А.А.

\section{СОВЕТСКАЯ МОЛОДЕЖЬ 1920-1930-х ГГ.: ДАЛЬНЕВОСТОЧНЫЙ РАКУРС (Рецензия на книгу: Билим Н. Н. Молодежное движение и государственная молодежная политика на Советском Дальнем Востоке (ноябрь 1922 - июнь 1941). Хабаровск: Хабаровский пограничный институт ФСБ России, 2013. 212 с.)}

Аннотация: В статье рецензируется монография Натальи Николаевны Билим, посвященная молодежному движению и государственной молодежной политике на советском Дальнем Востоке в 1920-1930-е г2. (Билим Н. Н. Молодежное движение и государственная молодежная политика на Советском Дальнем Востоке (ноябрь 1922 - июнь 1941). Хабаровск: Хабаровский пограничный институт ФСБ России, 2013. 212 с.) Актуальность данной темы обусловлена не только историографической значимостью периода, во время которого закладывались основы советской политической системы, но и очень слабой осведомленностью современных историков о реалиях жизни молодежи 1920-1930-х г2. Созданные в СССР идеологические построения историков комсомола в совокупности с очернительскими опусами кония 1980-х-1990-х гг. создали много мифов, но мало продвинули нас 6 постижении истины. С точки зрения рецензента, вопросы об эффективности работы комсомола не должны оцениваться в простой дихотомии «эффективно-неэффективно», тем более, с позиций самих коммунистических организаџий. Призывая оценивать опыт комсомола с общечеловеческих и государственных позиций, смотреть на него как можно более многосторонне, рецензент отмечает. что, по крайней мере, предпосылки для этого в рецензируемой книге присутствуют. Хотя сам рецензент рассматривает систему идейно-политического воспитания молодежи в первую очередь как звено советской системы политического контроля, как объективные он рассматривает утверждения Н.Н. Билим о тесной связи пропагандистской деятельности комсомола с задачами по ликвидаџии неграмотности, попытками преодоления пьянства, распущенности, национализма. Достоинством книги называется научная критика публикаций, в которых комсомол предстает, как организачия, где отсутствовал какой-либо созидательный потенциал. Вместе с тем, отмечены и недостатки самой рецензируемой монографии.

Review: The article contains the review of Natalya Nikolaevna Bilim's monograph devoted to the youth movement and state youth policy in the Soviet Far East in the 1920th - 1930th (see Bilim, N. N. 'Youth Movement and State Youth Policy in the Soviet Far East (November 1922 - June 1941)' published in Khabarovsk at Khabarovsk Border Institute of the Federal Security Service of the Russian Federation in 2013). The importance of the topic is dictated not only by the historiographical significance of that period when the basis of the Soviet political system was founded but also by the poor awareness of modern historians on the real life of the youth of the 1920th - 1930th. Ideologies created by the USSR Komsomol historians together with the accusatory writings of the late 1980th-1990th created many myths but did not bring us any closer to the truth. According to the reviewer, the efficiency of Komsomol activities should not be evaluated from the plain 'efficient-inefficient' point of view, especially by the communist organizations themselves. Encouraging us to evaluate the Komsomol activities from the point of view of universal and state values, the reviewer notes that at least the book under review had certain prerequisites for that. Even though 
the reviewer sees the system of the ideological and political education of the youth as an element of the Soviet system of political control, he agrees to Natalya Bilim's statement about the close relation between propaganda efforts of Komsomol and the tasks of literacy and overcoming drunkenness, immorality and nationalism. The true advantage of the book is the scientific criticism of publications and articles showing Komsomol as an organization with no creative potentials at all. At the same time, the reviewer also describes the minuses of the monograph under review. Ключевые слова: История, историография, молодежь, комсомол, Дальний Восток, рецензия, идеология, религия, молодежная политика, созидание.

Keywords: History, historiography, youth, Komsomol, Far East, review, ideology, religion, youth policy, creation.

$\mathrm{K}$ сожалению, в последние годы отечественные историки чрезвычайно редко в своих книгах обращаются к истории молодежного движения в послереволюционной России. Между тем, актуальность данной темы обусловлена не только историографической значимостью периода, во время которого закладывались основы советской политической системы, но и очень слабой осведомленностью современных историков о реалиях жизни молодежи 1920-1930-х гг. (Вполне объективную картину изучения ювенальной истории дают историографические обзоры $\left.{ }^{12345}\right)$. Созданные в СССР идеологические построения историков комсомола в совокупности с очернительскими опусами конца 1980-х-1990-х гг. создали много мифов, но мало продвинули нас в постижении истины. Отечественная историография новейшего времени может гор-

${ }^{1}$ Демидова Е. И., Васильев А. А. Внимание к прошлому как залог успешного будущего российской молодежи // Исторические, философские, политические и юридические науки, культурология и искусствоведение. Вопросы теории и практики. 2011. № 6. Ч. 3. С. 211-217.

2 Двухжилова И. В. Вклад тамбовских ученых в исследование молодежного движения // Исторические, философские, политические и юридические науки, культурология и искусствоведение. Вопросы теории и практики. 2011. № 5. Ч. 3. C. 46-51.

3 Лукин М. А. Советская молодежь как объект и субъект политического контроля: современная историография проблемы // Исторические, философские, политические и юридические науки, культурология и искусствоведение. Вопросы теории и практики. 2011. № 4. Ч.1. С. 99-103

${ }^{4}$ Слезин A. A. Современные исследования о становлении советской политической системы // Право и политика. 2010. № 6. C. 1171-1180.

${ }_{5}^{5}$ Щупленков О. В. История молодежного движения в России в современном исследовательском поле // Исторические, философские, политические и юридические науки, культурология и искусствоведение. Вопросы теории и практики. 2012. № 1. Ч. 2. С. 211-215. диться книгами А.Ю. Рожкова ${ }^{6}$ и В. И. Соколова ${ }^{7}$ Появились региональные публикации, использующие недоступные ранее документы. Однако закрыть все лакуны в исследовании темы и им, конечно, было непосильно. Тем более, что в основном в них использовался материал Центральной России. В этой связи привлекает внимание выход в свет монографии Натальи Николаевны Билим, активно использующей материал Дальнего Востока ${ }^{8}$.

Российское молодежное движение рассматривается в ней в контексте всей отечественной истории 1920-1930-х гг., в первую очередь, социально-экономической и политической. Автор намеренно выделяет молодежь как мобильную и восприимчивую к новому социальную группу, обладающую необходимыми качествами для ответа на вызовы времени. По мнению автора, «от степени активности молодых людей, их социализации во многом зависело социально-экономическое и политическое развитие общества и государства» ${ }^{9}$.

К сожалению, параграф 2.1 «Молодежное движение в истории России» в большей степени наполнен уже не раз встречающейся в исследованиях по ювенальной истории информацией о деятельности столичной молодежи. Достоинством параграфа является научная критика всту-

\footnotetext{
${ }^{6}$ Рожков А. Ю. В кругу сверстников. Жизненный мир молодого человека в советской России 1920-х годов: в 2-х т. Краснодар: ОИПЦ «Перспективы образования», 2002.

7 Соколов В. И. История молодежного движения России (CССР) со второй половины XIX до XXI века. Рязань: Узорочье, 2002.

${ }^{8}$ Билим Н. Н. Молодежное движение и государственная молодежная политика на Советском дальнем Востоке (ноябрь 1922 - июнь 1941). Хабаровск: Хабаровский пограничный институт ФСБ России, 2013.

${ }^{9}$ Билим Н. Н. Молодежное движение и государственная молодежная политика... С. 11.
} 


\section{Политика и общество 8 (116) • 2014}

пительной статьи П. Деркаченко к сборнику документов «Молодежное движение России в документах (1905-1938 гг.) $)^{10}$, в которой комсомол предстает, как организация, где отсутствовал какой-либо созидательный потенциал.

В параграфе 2.2 «Молодежное движение на советском Дальнем Востоке: идейные и организационные основы» привлекает внимание характеристика объединений учащейся молодежи, скаутских организаций Сибири и Дальнего Востока. Правда, несколько удивляет применение терминов советской историографии («непролетарские партии»).

Данные о деятельности комсомольских организаций в начале 1920-х годов представлены слишком фрагментарно. Иногда подаваемые в качестве отдельных примеров они вряд ли могут служить основой обобщений и выводов. Пожалуй, автору необходимо было обратить более серьезное внимание на необходимость соблюдения хронологической последовательности в изложении фактов.

Интересны привлеченные Н. Н. Билим материалы конфликтных окружных и районных комиссий РКСМ, исследование статистики привлечения в комсомол представителей национальных меньшинств (китайцев, корейцев, представителей народов Севера).

В главе 3 «Формирование и развитие советской молодежной политики в 1922-1941 гг.» показано, что в исследуемый период приоритетным направлением советской государственной политики была забота о подрастающем поколении, о его образовании, всестороннем воспитании, охране труда и здоровья. Особо обращается внимание на разработку системы контроля и ответственности должностных лиц за исполнением нормативно-правовых актов, охранявших интересы молодежи. Как основные результаты советской молодежной политики выделены ликвидация неграмотности и малограмотности среди подростков и юношества, наличие у большинства молодежи постоянного места работы и гарантированного заработка, улучшение медицинской помощи и спад уровня смертности молодежи.

Н.Н. Билим отмечает специфику форм и методов государственной молодежной политики на Дальнем Востоке. В частности, она связывает ее с нехваткой населения и рабочих кадров, в силу

${ }^{10}$ Молодежное движение России в документах (1905-1938 гг.). М. : ОМП-press, 1999. 383 c. чего основное внимание уделялось подрастающему поколению как главному резерву рабочего класса. Отмечена огромная работа по ликвидации неграмотности и борьбе с беспризорностью. Уделено внимание работе Дальневосточного Общества Друзей Детей, Дальневосточной детской комиссии при Дальревкоме, комиссий по улучшению жизни детей, занимавшихся трудоустройством подростков, их здоровьем и образованием, организацией детских учреждений. Н. Н. Билим обращает внимание на недостатки в работе детских учреждений, но в целом положительно оценивает работу на данном направлении. В книге справедливо отмечено, что при распределении мест в дома отдыха, санатории, пионерские лагеря обязательно учитывались интересы воспитанников детских домов ${ }^{11}$. Вполне убедительно звучит возражение Ю. А. Стецуре, провозгласившему, что советская система образования и воспитания формировала не творчески активную личность, а унифицированную, основанную на исполнительстве $^{12}$ : «Не способные творчески мыслить и работать люди не могли создать передовое производство, культуру, науки, вывести СССР в разряд передовых стран мира» ${ }^{13}$.

Комсомол охарактеризован как шеф всеобуча. Показаны трудности и достижения в развитии системы профессионального образования на Дальнем Востоке. Интересны сведения о Юхтинской трудовой коммуне, созданной в 1932 г. близ г. Свободный, и образованной в 1935 г. детской трудовой коммуне на о.Рейник.

Глава 4 монографии рассматривает основные направления идейно-политического воспитания молодежи Дальнего Востока. Н.Н. Билим признает наличие в системе идейно-политического воспитания политических манипуляций, направленных на формирование стереотипов поведения, но фактически оправдывает их необходимость решения поставленных грандиозных задач ${ }^{14}$. Автор выражает соли-

\footnotetext{
${ }^{11}$ Билим Н. Н. Молодежное движение и государственная молодежная политика... С. 118.

${ }^{12}$ Стеиура Ю.А. Молодежь в постреволюционном преобразовании России в 20 - 30-е годы. М., 1998. С. 170-171.

${ }^{13}$ Билим Н. Н. Молодежное движение и государственная молодежная политика... С. 121.

${ }^{14}$ Билим Н. Н. Молодежное движение и государственная молодежная политика... С. 132.
} 
дарность с мнением Ш.Фицпатрик, считавшей, что в ответ официозу «граждане выработали собственную стратегию оценки информации» ${ }^{15}$.

Хотя сам рецензент склонен рассматривать систему идейно-политического воспитания молодежи в первую очередь как звено советской системы политического контроля ${ }^{1617}$, трудно отрицать утверждения Н.Н. Билим о тесной связи пропагандистской деятельности комсомола с задачами по ликвидации неграмотности, попытками преодоления пьянства, распущенности, антисемитизма, национализма.

С учетом конкретных методов антирелигиозной работы комсомола ${ }^{1819}$ удивляет соседство с перечисленными явлениями «религиозных предрассудков». Впрочем, и сама Н.Н. Билим приходит к выводу, что агитационно-массовые формы борьбы с религией, применявшиеся комсомолом, не только не имели положительных результатов, но зачастую отталкивали как молодежь, так и представителей старших поколений ${ }^{20}$.

Значительно более сложные процессы, чем отмечено в книге, с нашей точки зрения, происходили и в сфере пропаганды нового положения женщины в обществе ${ }^{21}$.

15 Фицุпатрик Ш. Еще раз о повседневном сталинизме: Советская Россия в 1930-1950-е гг. // История сталинизма: итоги и проблемы изучения: Материалы международной научной конференции. Москва, 5-7 декабря 2008 г. М., 2011. С. 57.

16 Слезин A. A. Политическое просвещение молодежи 1920 -х годов как звено системы политического контроля // Политика и общество. 2010. № 3. С.52-59.

17 Слезин А.А. Специфика политико-просветительсной работы среди молодежи российской провинции в конце 1950-х годов // Политика и Общество. - 2014. - №5. - С. 598 - 606. DOI: 10.7256/1812-8696.2014.5.12219. URL: http:// www.nbpublish.com/go_to_article.php?id=29639.

${ }^{18}$ Слезин А.А. За «новую веру». Государственная политика в отношении религии и политический контроль среди молодежи РСФСР (1918-1929 гг.). М.: Издат.дом Академия естествознания, 2009. 214 с.

19 Слезин А.А., Баланцев А.В. Особенности противодействия комсомольских организаций религиозному влиянию среди «восточных национальных меньшинств» в середине 1920-х годов // Политика и Общество. - 2013. - №3. - С. 294 - 304. DOI: 10.7256/18128696.2013.03.5. URL:http://www.nbpublish.com/go_to_article.php?id=23845.

${ }^{20}$ Билим Н. Н. Молодежное движение и государственная молодежная политика... С. 176.

${ }^{21}$ Скоропад А.Э. «Одевичивание» комсомола как составляющая политического контроля // Вопросы современной науки и практики. Университет им. В.И. Вернадского. 2013. №2. С. 234-238.
Вопрос об эффективности идейно-политического воспитания не должен оцениваться в простой дихотомии «эффективно-неэффективно». Вряд ли вслед за автором рецензируемой монографии можно оценивать его эффективность с позиций самих коммунистических организаций. В качестве альтернативного метода более объективной оценки реализации воспитательной функции комсомола можно, например, предложить концепцию основ концепции воспитания жизнеспособных поколений И.М. Ильинского 22.

Сегодня важно оценить опыт комсомола с общечеловеческих и государственных позиций, причем посмотреть на него как можно более многосторонне. По крайней мере, предпосылки для этого в рецензируемой книге присутствуют. Противопоставляя свою позицию мнению К.Кур-Королев ${ }^{23}$, автор данной монографии заявляет, что подрастающее поколение СССР восприняло новую идеологию, отрицает утверждение о том, что советский человек был простым «винтиком» государственной машины: «Мечтая о будущем, молодые люди реально изменяли жизнь, не только личную, но и всей страны» ${ }^{24}$. Здравое ядро здесь присутствует хотя бы в том, что автор рецензируемой книги не забыват про созидательные традиции советской молодежи 1920-1930-х гг. В отличие от стереотипных подходов советского периода Н. Н. Билим использует не только «светлые краски», но при этом настойчиво уходит от использования лишенных аргументации крайне негативных оценок.

\footnotetext{
${ }^{22}$ Ильинский И.М. Основы концепции воспитания жизнеспособных поколений [Электронный ресурc]. URL: http://www. ilinskiy.ru/publications/sod/konts-vosp-5.php (Дата обращения: 1.08.2014)

${ }^{23}$ Kuhr-Korolev C. «Gezahmte Helden». Die Formierung der Sowjetjugend 1917-1932. Essen, 2005.

${ }^{24}$ Билим Н. Н. Молодежное движение и государственная молодежная политика... С. 159.
} 


\section{Политика и общество 8 (116) • 2014}

\section{Библиография:}

1. Билим Н. Н. Комсомол и атеистическое воспитание молодежи в 1920-е гг. (региональный аспект) // Исторические, философские, политические и юридические науки, культурология и искусствоведение. Вопросы теории и практики. 2014. №3. Ч. 1. С. 33-36.

2. Билим Н. Н. Молодежное движение и государственная молодежная политика на Советском Дальнем Востоке (ноябрь 1922 - июнь 1941). Хабаровск: Хабаровский пограничный институт ФСБ России, 2013. 212 с.

3. Двухжилова И. В. Вклад тамбовских ученых в исследование молодежного движения // Исторические, философские, политические и юридические науки, культурология и искусствоведение. Вопросы теории и практики. 2011. № 5. Ч. 3. С. 46-51.

4. Демидова Е. И., Васильев А. А. Внимание к прошлому как залог успешного будущего российской молодежи // Исторические, философские, политические и юридические науки, культурология и искусствоведение. Вопросы теории и практики. 2011. № 6. Ч. 3. С. 211-217.

5. Ильинский И.M. Основы концепции воспитания жизнеспособных поколений [Электронный pecypc]. URL: http:// www.ilinskiy.ru/publications/sod/konts-vosp-5.php (Дата обращения: 1.08.2014)

6. Лукин М. А. Советская молодежь как объект и субъект политического контроля: современная историография проблемы // Исторические, философские, политические и юридические науки, культурология и искусствоведение. Вопросы теории и практики. 2011. № 4. Ч.1. С. 99-103.

7. Москалев А. Е. Молодежные общественные объединения как форма артикуляции интересов молодежи и субъект политической социализации // Исторические, философские, политические и юридические науки, культурология и искусствоведение. Вопросы теории и практики. 2011. № 4. Ч.3. С. 112-116.

8. Молодежное движение России в документах (1905-1938 гг.). М. : OMП-press, 1999. 383 с.

9. Молодежь и время. Тюмень : Издательство Тюменского государственного университета, 1999.

10. Рожков А. Ю. В кругу сверстников. Жизненный мир молодого человека в советской России 1920-х годов: в 2-х т. Краснодар: ОИПЦ «Перспективы образования», 2002. Т.1. 408 с. Т. 2. 208 с.

11. Скоропад А.Э. «Одевичивание» комсомола как составляющая политического контроля // Вопросы современной науки и практики. Университет им. В.И. Вернадского. 2013. №2. С. 234-238.

12. Слезин А. А. За «новую веру». Государственная политика в отношении религии и политический контроль среди молодежи РСФСР (1918-1929 гг.). М.: Издат. дом Академия естествознания, 2009. 214 с.

13. Слезин А. А. Политическое просвещение молодежи 1920-х годов как звено системы политического контроля // Политика и общество. 2010. № 3. С.52-59.

14. Слезин А. А. Современные исследования о становлении советской политической системы // Право и политика. 2010. № 6. C. 1171-1180.

15. Слезин А.А., Чеботарев С.А., Провалова Л.В. и др. Тамбовский комсомол: грани истории. 1918-1945. Тамбов: Пролетарский светоч, 2008. 467 с.

16. Соколов В. И. История молодежного движения России (СССР) со второй половины XIX до XXI века. Рязань: Узорочье, $2002.626 \mathrm{c}$.

17. Стецура Ю. А. Молодежь в постреволюционном преобразовании России в 20-30-е годы. М.: Социум, 1998.179 с.

18. Щупленков О. В. История молодежного движения в России в современном исследовательском поле // Исторические, философские, политические и юридические науки, культурология и искусствоведение. Вопросы теории и практики. 2012. № 1. Ч. 2. С. 211-215.

19. Kuhr-Korolev C. «Gezahmte Helden». Die Formierung der Sowjetjugend 1917-1932. Essen, 2005.

20. Слезин А.А., Скоропад А.Э. Институализация комсомола как государственного органа // NB: Проблемы общества и политики. - 2013. - 4. - С. 185 - 208. DOI: 10.7256/2306-0158.2013.4.462. URL: http://www.e-notabene.ru/pr/article_462.html

21. Киричек А.И. Исследовательские социолого-политологические подходы к молодежной проблематике // NB: Проблемы общества и политики. - 2012. - 1. - C. 124 - 136. URL: http://www.e-notabene.ru/pr/article 22.html

22. А.А. Слезин, А.В. Баланцев Особенности противодействия комсомольских организаций религиозному влиянию среди «восточных национальных меньшинств» в середине 1920-х годов // Политика и Общество. - 2013. - 3. C. 294 - 304. DOI: 10.7256/1812-8696.2013.03.5.

23. Слезин А.А. Специфика политико-просветительсной работы среди молодежи российской провинции в конце 1950-х годов // Политика и Общество. - 2014. - 5. - С. 598 - 606. DOI: 10.7256/1812-8696.2014.5.12219.

\section{References (transliteration):}

1. Bilim N. N. Komsomol i ateisticheskoe vospitanie molodezhi v 1920-e gg. (regional'nyi aspekt) // Istoricheskie, filosofskie, politicheskie i yuridicheskie nauki, kul’turologiya i iskusstvovedenie. Voprosy teorii i praktiki. 2014. №3. Ch. 1. S. 33-36. 
2. Bilim N. N. Molodezhnoe dvizhenie i gosudarstvennaya molodezhnaya politika na Sovetskom Dal'nem Vostoke (noyabr' 1922 - iyun' 1941). Khabarovsk: Khabarovskii pogranichnyi institut FSB Rossii, 2013. 212 s.

3. Dvukhzhilova I. V. Vklad tambovskikh uchenykh v issledovanie molodezhnogo dvizheniya // Istoricheskie, filosofskie, politicheskie i yuridicheskie nauki, kul’turologiya i iskusstvovedenie. Voprosy teorii i praktiki. 2011. № 5. Ch. 3. S. 46-51.

4. Demidova E. I., Vasil'ev A. A. Vnimanie k proshlomu kak zalog uspeshnogo budushchego rossiiskoi molodezhi // Istoricheskie, filosofskie, politicheskie i yuridicheskie nauki, kul’turologiya i iskusstvovedenie. Voprosy teorii i praktiki. 2011. № 6. Ch. 3. S. 211-217.

5. Il'inskii I.M. Osnovy kontseptsii vospitaniya zhiznesposobnykh pokolenii [Elektronnyi resurs]. URL: http://www.ilinskiy. ru/publications/sod/konts-vosp-5.php (Data obrashcheniya: 1.08.2014)

6. Lukin M. A. Sovetskaya molodezh' kak ob' 'ekt i sub"'ekt politicheskogo kontrolya: sovremennaya istoriografiya problemy // Istoricheskie, filosofskie, politicheskie i yuridicheskie nauki, kul'turologiya i iskusstvovedenie. Voprosy teorii i praktiki. 2011. № 4. Ch.1. S. 99-103.

7. Moskalev A. E. Molodezhnye obshchestvennye ob'edineniya kak forma artikulyatsii interesov molodezhi i sub' 'ekt politicheskoi sotsializatsii // Istoricheskie, filosofskie, politicheskie i yuridicheskie nauki, kul'turologiya i iskusstvovedenie. Voprosy teorii i praktiki. 2011. № 4. Ch.3. S. 112-116.

8. Rozhkov A. Yu. V krugu sverstnikov. Zhiznennyi mir molodogo cheloveka v sovetskoi Rossii 1920-kh godov: v 2-kh t. Krasnodar: OIPTs "Perspektivy obrazovaniya", 2002. T.1. 408 s. T. 2. 208 s.

9. Skoropad A.E. «Odevichivanie» komsomola kak sostavlyayushchaya politicheskogo kontrolya // Voprosy sovremennoi nauki i praktiki. Universitet im. V.I. Vernadskogo. 2013. №2. S. 234-238.

10. Slezin A. A. Za «novuyu veru». Gosudarstvennaya politika v otnoshenii religii i politicheskii kontrol' sredi molodezhi RSFSR (1918-1929 gg.). M.: Izdat. dom Akademiya estestvoznaniya, 2009. $214 \mathrm{~s}$.

11. Slezin A. A. Politicheskoe prosveshchenie molodezhi 1920-kh godov kak zveno sistemy politicheskogo kontrolya // Politika i obshchestvo. 2010. № 3. S.52-59.

12. Slezin A. A. Sovremennye issledovaniya o stanovlenii sovetskoi politicheskoi sistemy // Pravo i politika. 2010. № 6. S. 1171-1180.

13. Slezin A.A., Chebotarev S.A., Provalova L.V. i dr. Tambovskii komsomol: grani istorii. 1918-1945. Tambov: Proletarskii svetoch, 2008. $467 \mathrm{~s}$.

14. Sokolov V. I. Istoriya molodezhnogo dvizheniya Rossii (SSSR) so vtoroi poloviny XIX do XXI veka. Ryazan': Uzoroch'e, 2002. $626 \mathrm{~s}$.

15. Stetsura Yu. A. Molodezh' v postrevolyutsionnom preobrazovanii Rossii v 20-30-e gody. M.: Sotsium, 1998.179 s.

16. Shchuplenkov O. V. Istoriya molodezhnogo dvizheniya v Rossii v sovremennom issledovatel'skom pole // Istoricheskie, filosofskie, politicheskie i yuridicheskie nauki, kul’turologiya i iskusstvovedenie. Voprosy teorii i praktiki. 2012. № 1. Ch. 2. S. 211-215.

17. Kuhr-Korolev C. «Gezahmte Helden». Die Formierung der Sowjetjugend 1917-1932. Essen, 2005.

18. Slezin A.A., Skoropad A.E. Institualizatsiya komsomola kak gosudarstvennogo organa // NB: Problemy obshchestva i politiki. - 2013. - 4. - C. 185 - 208. DOI: 10.7256/2306-0158.2013.4.462. URL: http://www.e-notabene.ru/pr/article_462.html

19. Kirichek A.I. Issledovatel'skie sotsiologo-politologicheskie podkhody k molodezhnoi problematike // NB: Problemy obshchestva i politiki. - 2012. - 1. - C. $124-136$. URL: http://www.e-notabene.ru/pr/article_22.html

20. A.A. Slezin, A.V. Balantsev Osobennosti protivodeistviya komsomol'skikh organizatsii religioznomu vliyaniyu sredi «vostochnykh natsional'nykh men'shinstv» v seredine 1920-kh godov // Politika i Obshchestvo. - 2013. - 3. - C. 294 304. DOI: $10.7256 / 1812-8696.2013 .03 .5$.

21. Slezin A.A. Spetsifika politiko-prosvetitel'snoi raboty sredi molodezhi rossiiskoi provintsii v kontse 1950-kh godov // Politika i Obshchestvo. - 2014. - 5. - C. 598 - 606. DOI: 10.7256/1812-8696.2014.5.12219. 